\title{
FIXED POINT THEOREMS IN GENERALIZED BANACH ALGEBRAS AND APPLICATIONS
}

\author{
JUAN J NIETO*, ABDELGHANI OUAHAB** AND ROSANA RODRÍGUEZ-LÓPEZ* \\ *Departamento de Análise Matemática, Estatística e Optimización \\ Facultade de Matemáticas \\ Universidade de Santiago de Compostela, Santiago de Compostela, 15782, Spain \\ E-mail: juanjose.nieto.roig@usc.es, rosana.rodriguez.lopez@usc.es \\ ** Laboratory of Mathematics, Sidi-Bel-Abbès University \\ PoBox 89, 22000 Sidi-Bel-Abbès, Algeria \\ E-mail: agh_ouahab@yahoo.fr, abdelghani.ouahab@univ-sba.dz
}

\begin{abstract}
In this paper, we prove some fixed point theorems in vector algebra Banach spaces. We establish the versions of Perov, Schauder and Krasnosel'skki type fixed point theorem for the sum of a contraction operator and a compact operator. The obtained results are applied to prove some theorems on the existence of solutions to nonlinear integral equations in Banach algebras. Finally, some example are given to illustrate the result.
\end{abstract}

Key Words and Phrases: Generalized Banach space, algebra Banach space, fixed point, multivalued map, matrix, fractional integral equation.

2010 Mathematics Subject Classification: 47H10, 47H30, 54H25.

Acknowledgement. This paper was completed while A. Ouahab visited the Department of Mathematical Analysis of the University of Santiago de Compostela. He would like to thank the department for its hospitality and support. The research has been partially supported by Ministerio de Economía y Competitividad (Spain), project MTM2013-43014-P, AEI of Spain under grant MTM2016-75140-P, and Xunta de Galicia under grants GRC2015/004 and R2016-022. The authors would like to thank the anonymous referees for their careful reading of the manuscript and pertinent comments; their constructive suggestions substantially improved the quality of the work.

\section{REFERENCES}

[1] J. Andres, L. Górniewicz, Topological Fixed Point Principles for Boundary Value Problems, Kluwer, Dordrecht, 2003.

[2] J.P. Aubin, H. Frankowska, Set-Valued Analysis, Birkhauser, Boston, 1990.

[3] J. Banas, L. Lecko, Fixed points of the product of operators in Banach algebras, Panamer. Math. J., 12(2002), 101-109.

[4] J. Banas, L. Olszowy, On a class of measures of non-compactness in Banach algebras and their application to nonlinear integral equations, Z. Anal. Anwend., 28(2009), 475-498. 
[5] J. Banas, B. Rzepka, Monotonic solutions of a quadratic integral equation of fractional order, J. Math. Anal. Appl., 332(2007), 1371-1379.

[6] J. Banas, K. Sadarangani, Solutions of some functional-integral equations in Banach algebras, Math. Comput. Modelling, 38(2003), 245-250.

[7] A. Ben Amar, D. O'Regan, Topological Fixed Point Theory for Singlevalued and Multivalued Mappings and Applications, Springer, 2016.

[8] A. Ben Amar, M. Boumaiza, D. O'Regan, Hybrid fixed point theorems for multivalued mappings in Banach algebras under a weak topology setting, J. Fixed Point Theory Appl., 18(2016), 327350.

[9] A. Ben Amar, S. Chouayekh, A. Jeribi, Fixed point theory in a new class of Banach algebras and application, Afr. Mat., 24(2013), 705-724.

[10] A. Ben Amar, S. Chouayekh, A. Jeribi, New fixed point theorems in Banach algebras under weak topology features and applications to nonlinear integral equations, J. Funct. Anal., 259(2010), 2215-2237.

[11] H.F. Bohnenblust, S. Karlin, On a theorem of Ville, in: Contributions to the Theory of Games, Annals of Mathematics Studies, Vol. 24, Princeton Univ. Press, Princeton, 1950, 155-160.

[12] K. Deimling, Multi-valued Differential Equations, De Gruyter, Berlin-New York, 1992.

[13] B.C. Dhage, Remarks on two fixed point theorems involving the sum and the product of two operators, Comput. Math. Appl., 46(2003), 1779-1785.

[14] B.C. Dhage, Multi-valued operators and fixed point theorems in Banach algebras, I, Taiwanese J. Math., 10(2006), 1025-1045.

[15] B.C. Dhage, Multivalued operators and fixed-point theorems in Banach algebras, II, Comput. Math. Appl., 48(2004), 1461-1476.

[16] S. Djebali, L. Gorniewicz, A. Ouahab, Solutions Sets for Differential Equations and Inclusions, De Gruyter Series in Nonlinear Analysis and Applications 18, Berlin, W. de Gruyter, 2013.

[17] L. Górniewicz, Topological Fixed Point Theory of Multi-valued Mappings, 495, Kluwer Acad. Publ., Dordrecht, 1999.

[18] A. Granas, J. Dugundji, Fixed Point Theory, Springer, New York, 2003.

[19] D. Henry, Geometric Theory of Semilinear Parabolic Partial differential Equations, SpringerVerlag, Berlin-New York, 1989.

[20] Sh. Hu, N.S. Papageorgiou, Handbook of Multi-valued Analysis, Volume I: Theory, Kluwer, Dordrecht, 1997.

[21] Sh. Hu, N.S. Papageorgiou, Handbook of Multi-valued Analysis. Volume II: Applications, Kluwer, Dordrecht, The Netherlands, 2000.

[22] M. Kamenskii, V. Obukhovskii, P. Zecca, Condensing multi-valued Maps and Semilinear Differential Inclusions in Banach Spaces, Walter de Gruyter \& Co. Berlin, 2001.

[23] D. O'Regan, R. Precup, Theorems of Leray-Schauder Type and Applications, Gordon and Breach, Amsterdam, 2001.

[24] A. Ouahab, Some Perov's and Krasnosel'skii type fixed point results and application, Comm. Appl. Nonlinear Anal., 19(2015), 623-642.

[25] A.I. Perov, On the Cauchy problem for a system of ordinary differential equations, (in Russian), Pribliz. Met. Reshen. Differ. Uravn., 21964, 115-134.

[26] A.I. Perov, A.V. Kibenko, On a certain general method for investigation of boundary value problems, (in Russian), Izv. Akad. Nauk SSSR, Ser. Mat., 30(1966), 249-264.

[27] I.R. Petre, A. Petruşel, Krasnoselskii's theorem in generalized Banach spaces and applications, Electron. J. Qual. Theory Differ. Equ., 85(2012), 20 pp.

[28] I.R. Petre, A multivalued version of Krasnoselskii's theorem in generalized Banach spaces, An. Şt. Univ. Ovidius Constanţa, 22(2014), 177-19.

[29] R. Precup, Methods in Nonlinear Integral Equations, Kluwer Academic Publishers, Dordrecht, 2002.

[30] M.L. Sinacer, J.J. Nieto, A. Ouahab, Random fixed point theorem in generalized Banach space and applications, Random Oper. Stoch. Equ., 24(2016), 93-112.

[31] A.A. Tolstonogov, Differential Inclusions in Banach Spaces, Kluwer, Dordrecht, 2000. 
[32] R.S. Varga, Matrix Iterative Analysis, Second Revised and Expanded Edition, Springer Series in Computational Mathematics, 27, Springer-Verlag, Berlin, 2000.

[33] A. Viorel, Contributions to the Study of Nonlinear Evolution Equations, Ph.D. Thesis, BabeşBolyai University Cluj-Napoca, Department of Mathematics, 2011.

[34] E. Zeidler, Nonlinear Functional Analysis and Applications. Fixed Point Theorems, SpringerVerlag, New York, 1986.

Received: August 10, 2016; Accepted: January 18, 2018. 